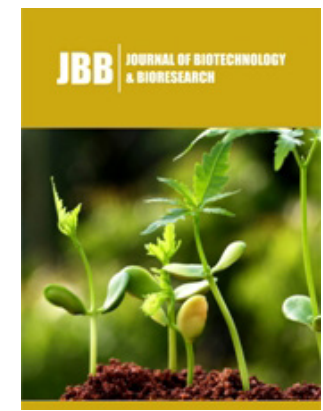

*Corresponding author: Jacob B Omajali, Department of Chemistry, Thompson Rivers University, Canada

Submission: 監 December 03, 2020

Published: 唒 December 22, 2020

Volume 2 - Issue 4

How to cite this article: Jacob $\mathrm{B}$ Omajali, Lynne E Macaskie. A Facile and Cost Effective Synthesis of BiomassSupported Palladium Nanoparticles Using Sodium Hypophosphite for Catalytic Dechlorination of Chlorobenzene. J Biotech Biores. 2(4). JBB. 000545. 2020

Copyright@ Jacob B Omajali, This article is distributed under the terms of the Creative Commons Attribution 4.0 International License, which permits unrestricted use and redistribution provided that the original author and source are credited.

\section{A Facile and Cost Effective Synthesis of Biomass-Supported Palladium Nanoparticles Using Sodium Hypophosphite for Catalytic Dechlorination of Chlorobenzene}

\author{
Jacob B Omajali1,2* and Lynne E Macaskie ${ }^{2}$ \\ ${ }^{1}$ Department of Chemistry, Thompson Rivers University, Kamloops, Canada
}

${ }^{2}$ Unit of Functional Bio-nanomaterials, Institute of Microbiology and Infection, School of Biosciences, University of Birmingham, United Kingdom

\begin{abstract}
Although molecular hydrogen is very useful in environmentally clean technology, its usage also comes with some associated hazards and hence the need to use hydrogen donor compounds such as sodium hypophosphite in the generation of hydrogen as electron donor. In this study, sodium hypophosphite was utilized as a source of hydrogen and as an electron donor in the biogenic reduction of palladium onto the surface of bacterial cells (aerobic and anaerobic bacteria) to produce bio-nanoparticles with potential in the dehalogenation of chlorinated pollutants like chlorobenzene. The purpose of this paper is to provide a facile and cost effective approach to the synthesis of biogenic nanoparticles using sodium hypophosphite as a hydrogen donor compound.
\end{abstract}

\section{Introduction}

Hydrogen is a source of environmentally clean and sustainable energy of the future. It has great potential in power generation e.g. in polymer electrolyte membrane (PEM) fuel cell technology [1,2]. For more details on polymer membrane (PEM) fuel cell technology and applications, the reader is referred to an extensive review by Wang Y, et al. [3]. However, molecular hydrogen has been described as a gas of low molecular weight, high diffusibility with ease of ignition resulting in hazards, especially in large scale production [4]. Despite extensive efforts there is still no hydrogen storage method with a sufficiently high $\mathrm{H}_{2}$ /weight ratio. Hence, hydrogen donor compounds are becoming increasingly viable alternatives for both storage and generation of hydrogen gas, requiring no hydrogen vessels for storage and major challenges of containment and transport are avoided. Examples of such alternative hydrogen donor compounds include $\mathrm{NaBH}_{4}$, formic acid, formate and $\mathrm{NaH}_{2} \mathrm{PO}_{2}$ which are safer, environmentally greener alternatives and can be more easily handled than molecular hydrogen. The objective of this study was to investigate the use of sodium hypophosphite $\left(\mathrm{NaPO}_{2} \mathrm{H}_{2}\right)$ as a simple and cost-effective alternative source of hydrogen for the catalytic synthesis of palladium (Pd) nano-catalysts supported on bacteria and the subsequent application in reductive dehalogenation of chlorobenzene.

\section{Materials and Methods}

Bacillus benzeovorans NCIMB 12555 and Desulfovibrio desulfuricans NCIMB 8307 were grown according to the method of Omajali JB, et al. [5,6]. Cells were harvested by centrifugation followed by sorption of $\mathrm{Pd}(\mathrm{II})\left(30^{\circ} \mathrm{C}, 30 \mathrm{~min}\right)$ in a given volume of $\mathrm{Na}_{2} \mathrm{PdCl}_{4}$ ( $\mathrm{pH} 2$ adjusted with $0.01 \mathrm{M} \mathrm{HNO}_{3}$ ) to make a final $20 \mathrm{wt} \%$ bio-Pd (0) on cells. Reduction to Pd (0) was done with a $20 \mathrm{mM}$ solution of sodium hypophosphite $\left(\mathrm{NaPO}_{2} \mathrm{H}_{2}\right)$ from a $500 \mathrm{mM}$ stock without shaking the content. The reduction occurred immediately. Samples were washed with distilled water and prepared for various characterization techniques (TEM, XRD and XPS). The catalyst made by both $B$. benzeovorans and $D$. desulfuricans were compared in reductive dehalogenation of chlorobenzene as described by Omajali [6]. 


\section{Results and Discussion}

The reduction of palladium by both bacteria using sodium hypophosphite $\left(\mathrm{NaPO}_{2} \mathrm{H}_{2}\right)$ occurred almost immediately with black deposits of $\mathrm{Pd}$ on and within cells. The black deposits were examined using TEM (Figure 1) on D. desulfuricans and $B$. benzeovorans respectively. More Pd was found localized on the periplasm and outer membrane of D. desulfuricans than inside the cells while intracellular deposition was more apparent in $B$. benzeovorans. Similar palladium nanoparticle (Pd-NP) formation was reported by Omajali JB, et al. [5] using both formate and hydrogen as electron donors. Some larger Pd-particles were visible on the outside of the cells (Figure 1) which were not seen in the previous work [5]. In this study the Pd-NPs were confirmed as palladium via XRD (X-ray powder diffraction) (Figure 1). However, the average Pd crystallite size made by $B$. benzeovorans was larger $(10.7 \pm 069 \mathrm{~nm})$ than that made by $D$. desulfuricans $(8.7 \pm 0.94 \mathrm{~nm})$ determined from the XRD data [6]. This difference is very clear when the XRD patterns from both cells were compared; with bio-Pd (0) of D. desulfuricans producing mostly broader Pd peaks (Figure 1) than that of $B$. benzeovorans (Figure 1). The peak broadening in both bio-Pd (0) may be due to interaction of phosphorus (P) from the reductant $\left(\mathrm{NaPO}_{2} \mathrm{H}_{2}\right)$ with Pd, forming a PdP alloy on cells; using XRD a similar result was reported [7] in the synthesis of $\mathrm{PdP} /$ on carbon by $\mathrm{NaPO}_{2} \mathrm{H}_{2}$ reduction, leading to peak broadening.
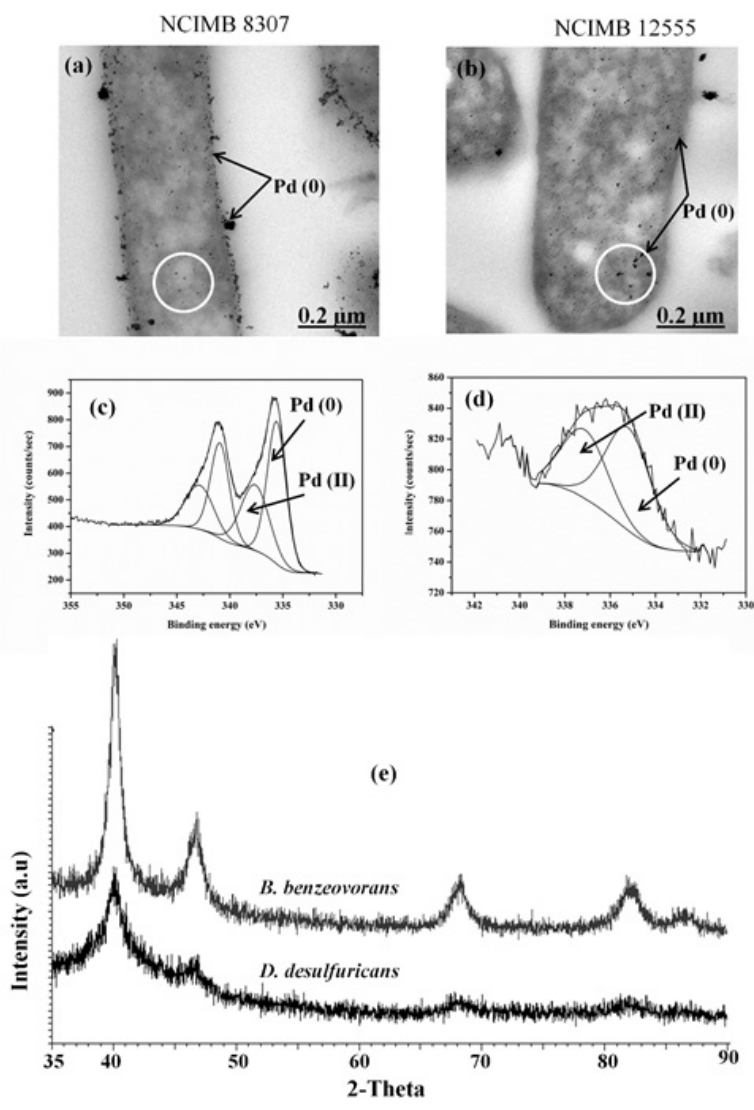

Figure 1: TEM images (a, b), XPS spectra of Pd 3d (c, d) and XRD (e) patterns of catalyst made via sodium hypophosphite mediated Pd (II) reduction on cells of $D$. desulfuricans (left) and $B$. benzeovorans (right). White circles highlight intracellular palladium nanoparticles.

X-ray photoelectron spectroscopy (XPS) provided information on the oxidation states and elemental composition of the surface of each catalyst made by both cells [8]. Both catalysts were reduced mostly to metallic palladium with corresponding binding energies at $335.6 \mathrm{eV}$ and $335.2 \mathrm{eV}$ for D. desulfuricans and B. benzeovorans respectively, with some residual palladium (II) occurring at binding energies of $337.6 \mathrm{eV}$ and $337.1 \mathrm{eV}$ (Figure 1). However, differences were apparent in 01s (Figure 2) and P2p (Figure 2) surface elements. There were shifts to higher binding energies ( $531.9 \mathrm{eV}$ and $533.2 \mathrm{eV}$ ) of the $01 \mathrm{~s}$ in the catalyst made by bio-Pd of $D$. desulfuricans compared to lower binding energies $(530.5 \mathrm{eV}$ and $532.1 \mathrm{eV}$ ) seen in B. benzeovorans. A similar difference seen with P2p shows two key binding energies of $134.33 \mathrm{eV}$ and 133.1 $\mathrm{eV}$ while three different peaks and binding energies at $132.5 \mathrm{eV}$, $133.81 \mathrm{eV}$ and $135.1 \mathrm{eV}$ were associated with B. benzeovorans. This difference in binding energy may be as a result of $\mathrm{Pd}$ interaction with phosphorus during Pd reduction with $\mathrm{NaPO}_{2} \mathrm{H}_{2}$. The differences in the surface elements are more prominent when the atomic concentrations were determined (Table 1). Reductive dehalogenation of chlorobenzene resulted in the removal of $82 \mathrm{mg} / \mathrm{L}$ of chloride (46.2\%) and 77.6mg/L (43.7\%) by bio-Pd made by $D$. desulfuricans and B. benzeovorans after 24h (Figure 3). The rate of 
removal after the first $30 \mathrm{~min}$ of reaction was faster $(0.072 \mathrm{mmol} /$ $\mathrm{min} / \mathrm{mg} \mathrm{Pd}$ ) for the catalyst made by $D$. desulfuricans than that made by $B$. benzeovorans $(0.04 \mathrm{mmol} / \mathrm{min} / \mathrm{mg}$ Pd). This preliminary investigation has shown that sodium hypophosphite can potentially be used as an alternative electron donor to molecular hydrogen in the reduction of biogenic palladium during the synthesis of Pd bionanoparticles. These newly synthesized bio-nanoparticles have demonstrated the ability to dehalogenate aromatic chlorinated pollutant such as chlorobenzene.

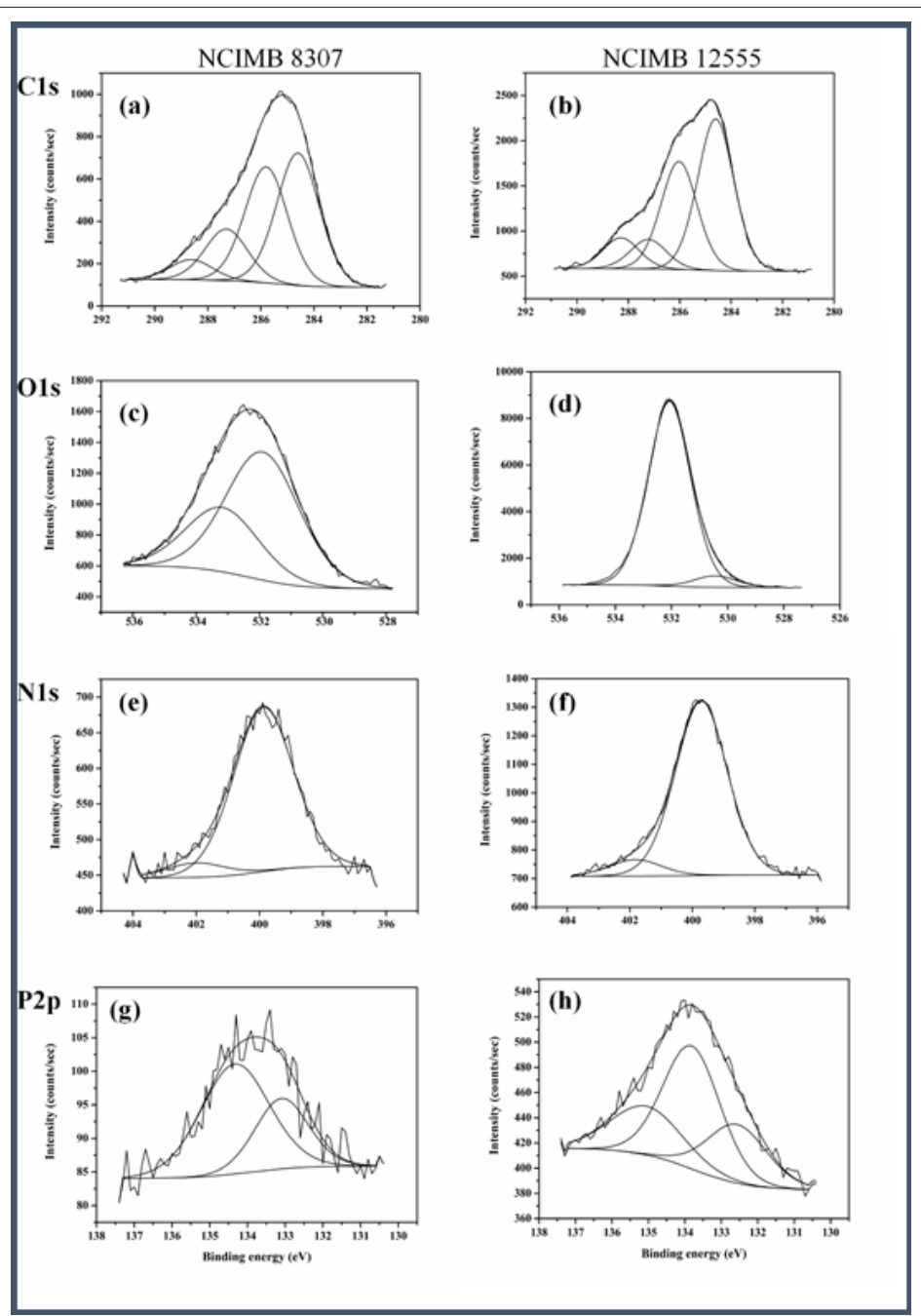

Figure 2: XPS spectra of surface composition of elements found on catalyst reduced via sodium hypophosphite by $D$. desulfuricans NCIMB 8307 (left) and B. benzeovorans NCIMB 12555 (right).

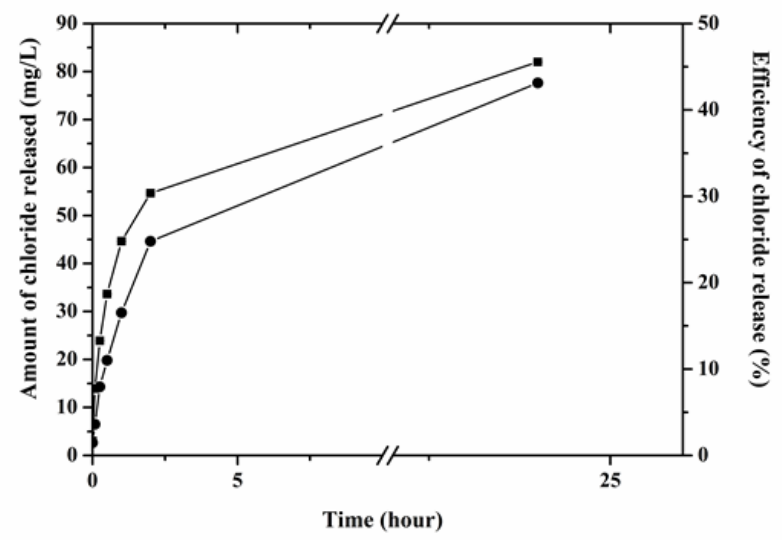

Figure 3: Efficiency and amount of chloride released by bio-Pd catalyst made by sodium hypophosphite reduction on cells of $D$. desulfuricans ( $)$ and B. benzeovorans (-) after $24 \mathrm{~h}$ of reductive dechlorination of chlorobenzene. 
Table 1: Atomic concentration of elements on catalyst surface made by bacteria after $\mathrm{Pd}$ (II) reduction with sodium hypophosphite analysed using XPS.

\begin{tabular}{|c|c|c|}
\hline \multirow{2}{*}{ Element } & \multicolumn{2}{|c|}{ Atomic Concentration (\%) } \\
\cline { 2 - 3 } & NCIMB 8307 & NCIMB 12555 \\
\hline C1s & 62.1 & 48 \\
\hline N1s & 6.7 & 6.1 \\
\hline 01s & 25.9 & 43.3 \\
\hline P2p & 0.95 & 2.43 \\
\hline
\end{tabular}

\section{Acknowledgement}

The authors acknowledge, with thanks, financial support from a Commonwealth Scholarship of the United Kingdom to JBO. The authors would also like to thank Marc Walker of the Department of Physics WarwickUniversity, United Kingdom forXPS dataacquisition and invaluable discussions. The Science City Photoemission Facility used in this research was funded through the Science City Advanced Materials Project 1: Creating and Characterizing Next Generation of Advanced Materials with support from AWM and ERDF funds.

\section{References}

1. Bose S, Kuila T, Xuan LN, Kim NH, Lau KT, et al. (2011) Polymer membranes for high temperature proton exchange membrane fuel cell: Recent advances and challenges. Progress in Polymer Science 36(6): 813-843.
2. Kocha SS (2017) Polymer electrolyte membrane (PEM) Fuel cells, automotive applications. In: Meyers R. (Eds.), Encyclopedia of Sustainability Science and Technology. Springer, New York, USA.

3. Wang Y, Chen KS, Mishler J, Cho SC, Adroher XC (2011) A review of polymer membrane fuel cells: Technology, applications and needs on fundamental research. Applied Energy 88(4): 982-1007.

4. Johnstone RAW, Wilby AH, Entwistle ID (1985) Heterogeneous catalytic transfer hydrogenation and its relation to other methods for reduction of organic compounds. Chemical Reviews 85(2): 129-170.

5. Omajali JB, Mikheenko IP, Merroun ML, Wood J, Macaskie LE (2015) Characterization of intracellular palladium nanoparticles synthesized by Desulfovibrio desulfuricans and bacillus benzeovorans. J Nanopart Res 17: 264.

6. Omajali JB (2015) Novel Bionanocatalysts for green chemistry applications. PhD Thesis, University of Birmingham, United Kingdom.

7. Omajali JB, Bolivar JG, Mikheenko IP, Sharma S, Kayode B, et al. (2019) Novel catalytically active $\mathrm{Pd} / \mathrm{Ru}$ bimetallic nanoparticles synthesized by bacillus benzeovorans. Scientific Reports 9: 4715.

8. Cheng L, Zhang Z, Niu W, Xu G, Zhu L (2008) Carbon-supported Pd nanocatalyst modified by non-metal phosphorus for the oxygen reduction reaction. Journal of Power Sources 182(1): 91-94. 